\title{
Development of a Quality Control Index of Cement Stabilized Road Structures Using Shear Wave Velocity
}

\author{
Susit Chaiprakaikeow ${ }^{1}$, Chitinsee Soponpong ${ }^{1}$, Jiraroth Sukolrat ${ }^{2}$ \\ ${ }^{1}$ Department of Civil Engineering, Faculty of Engineering, Kasetsart University \\ Bangkok, Thailand \\ Fengssck@ku.ac.th; Chitincy_wing@hotmail.com \\ ${ }^{2}$ Bureau of Road Research and Development, Department of Highway of Thailand \\ Bangkok, Thailand \\ Sjiraroth@hotmail.com
}

\begin{abstract}
The Department of Highways of Thailand has used cement stabilized materials as road base and subbase for more than 30 years. However, the quality control index of the construction is only undertaken by measuring Unconfined Compressive Strength (UCS) of materials after 7 days of curing. As the UCS test is a destructive and time-consuming method, this study sought to evaluate the use of using seismic waves to inspect material quality as a nondestructive and less time-consuming method which may serve as a basis for the establishment of a new quality control index using shear wave velocity $\left(\mathrm{V}_{\mathrm{S}}\right)$ measured from Free-Free Resonance (FFR) tests. Four types (360 samples) of cement stabilized materials including soil cement subbase, soil cement base, cement modified crushed rock base, and pavement recycling with cement ratios of 1,3 and $5 \%$ by weight were tested. The results indicated that $\mathrm{V}_{\mathrm{S}}$ increased nonlinearly with increasing UCS and also increased with increasing cement ratio for all materials. Moreover, at the same cement ratio, the $\mathrm{V}_{\mathrm{S}}$ and the UCS of cemented crushed rock base and pavement recycling were higher than soil cement materials because the first two materials had lower amounts of fine content. Quality controlled shear wave velocities were also calculated by doing a back analysis of developed $\mathrm{V}_{\mathrm{S}}$-UCS empirical equations, and were 536, 970, 1033 and $1095 \mathrm{~m} / \mathrm{sec}$ for constructions of soil cement subbase, soil cement base, cement modified crushed rock base, and pavement recycling, respectively.
\end{abstract}

Keywords: quality control, shear wave velocity, resonance, soil cement, unconfined compressive strength

\section{Introduction}

The Department of Highways of Thailand (DOH) has used Portland cement to improve soil quality in road base and subbase constructions for more than 30 years. However, the only quality control index of the construction is a measurement of Unconfined Compressive Strength (UCS) of cement stabilized materials after 7 days of curing. Because the UCS test is a destructive (coring is required) and time consuming method, the use of using seismic waves to inspect the material quality is valuable as it is a nondestructive and less time-consuming method. In order to obtain a high confidence of using low strain dynamic property (shear wave velocity) as a quality control index, the relationship between shear wave velocity and UCS of cement stabilized materials has to be developed.

In this study, shear wave velocity was measured by the Free-Free Resonance (FFR) test because of it's simplicity. At first, this technique was only used to test the stiffness of Portland cement [1] but over time the test has additionally been adapted for cement stabilized materials such as soil cement column [2]. This method is also a very reliable technique according to [10].

\section{Objectives}

There are 3 main objectives of this study. The first is to study the effect of the amount of cement on shear wave velocity and UCS of cement stabilized materials. The second is to develop empirical relationships between shear wave velocity and UCS of cement stabilized materials, and the third is to attain required shear wave velocity which will be used as a quality control index of constructions of cement stabilized materials. 


\section{Methodology}

\subsection{Basic Properties of Materials}

There were 4 materials used in this study including soil cement subbase, soil cement base, cement modified crushed rock base and pavement recycling. These materials were collected from 40 different material resources, 10 for each type . Their basic properties, without any addition of cement, comprising Liquid Limit, Plastic Limit, Plasticity Index, Sieve Analysis, Modified Proctor Compaction, Los Angeles Abrasion )for base materials(, California Bearing Ratio and Soundness )for crushed rocks (were tested to verify that their properties met DOH standards of cement stabilized materials [5] - [8] .Tested results of all materials are shown in Table 1 while grain size distributions of soil cement subbase, soil cement base, cement modified crushed rock base and pavement recycling are shown in Figure 1, Figure 2, Figure 3 and Figure 4, respectively.

\subsection{Sample Preparation}

Materials used in this study were all sieved through a number 4 sieve, mixed with cement at 1,3 , and $5 \%$ by weight, and compacted at optimum water content using developed mold and compaction hammer which were able to provide efficient energy equivalent to the Modified Proctor test .The size of the compacted samples was $0.05 \mathrm{~m}) 2$ inches( in diameter and $0.1 \mathrm{~m}) 4$ inches (in height.Three samples were tested at one cement ratio so there were a total of 360 tested samples in this analysis.

After compacting, the samples were put into plastic bags for curing for 7 days. The samples then were soaked in water for a couple hours before performing Free-Free Resonance )FFR (tests.

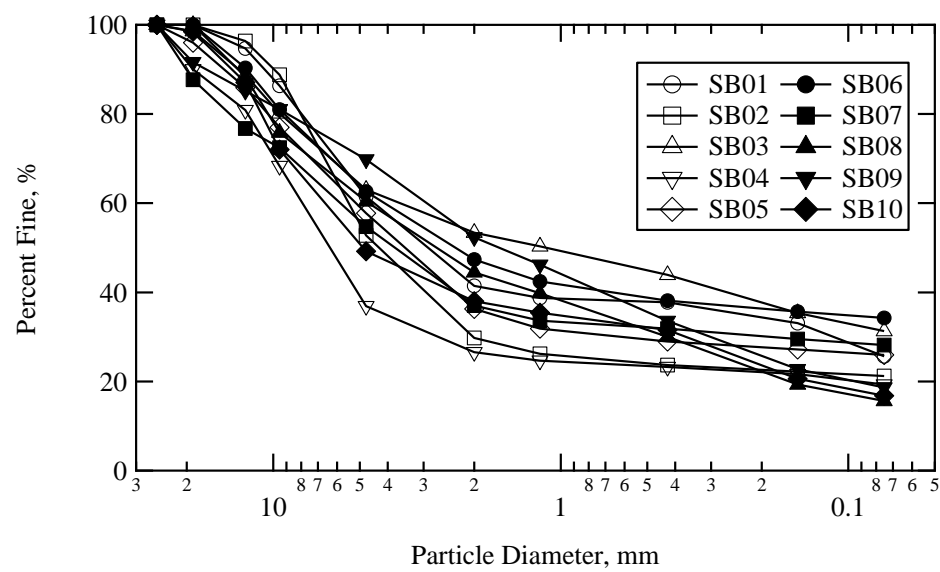

Fig. 1: Grain Size Distribution of Soil Cement Subbase.

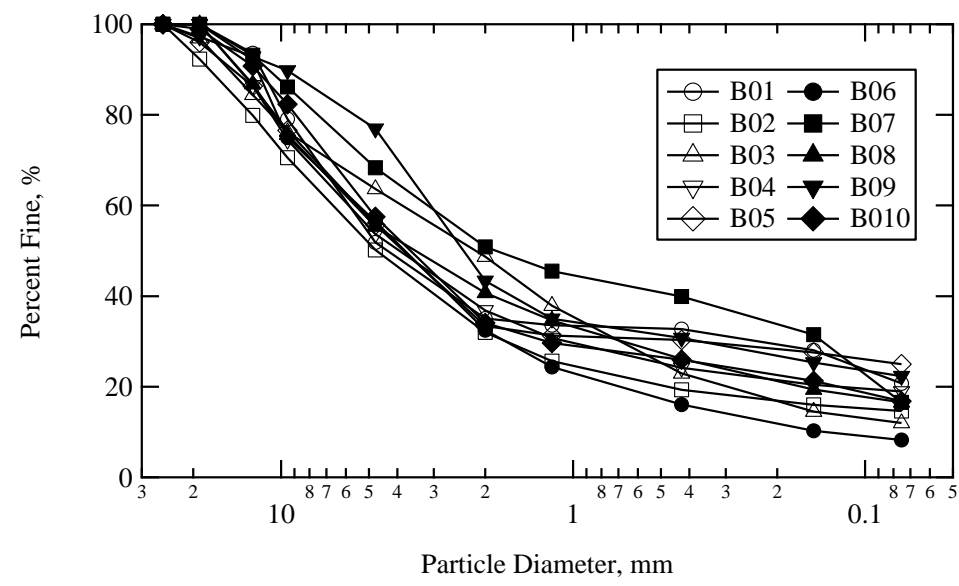

Fig. 2: Grain Size Distribution of Soil Cement Base. 


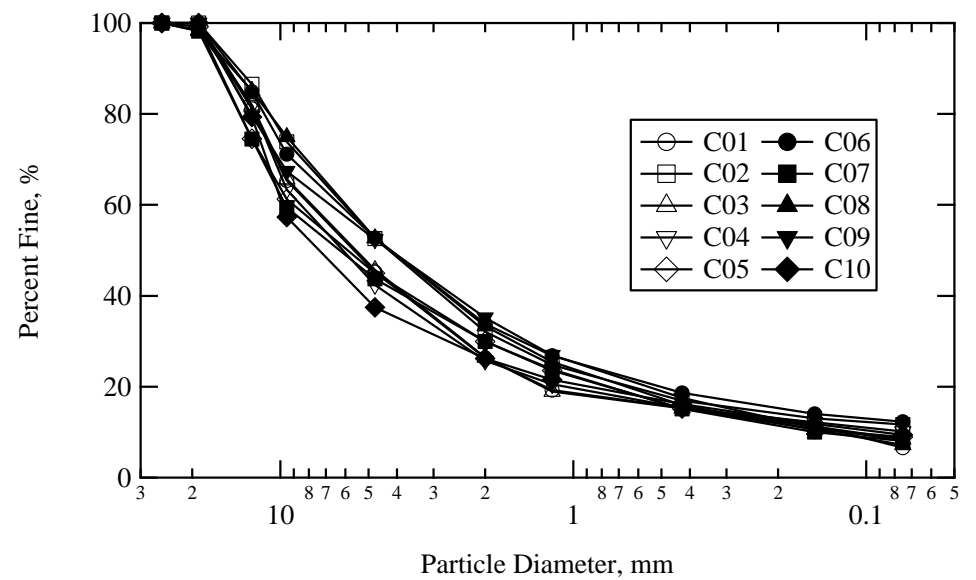

Fig. 3: Grain Size Distribution of Cement Modified Crushed Rock Base.

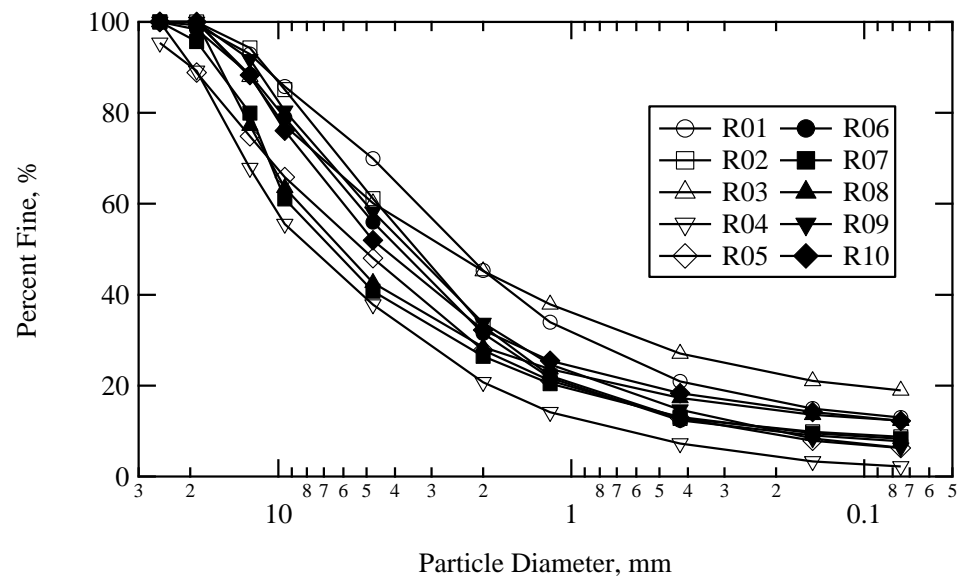

Fig. 4: Grain Size Distribution of Pavement Recycling. 
Table 1: Basic Properties of Materials.

\begin{tabular}{|c|c|c|c|c|c|c|c|c|c|c|}
\hline \multirow{3}{*}{ No } & \multirow{3}{*}{ Material Resource } & \multicolumn{2}{|c|}{ Compaction } & \multirow{3}{*}{$\begin{array}{c}\text { CBR } \\
\text { Unsoaked } \\
(\%)\end{array}$} & \multirow{3}{*}{$\begin{array}{c}\text { CBR } \\
\text { Soaked } \\
(\%)\end{array}$} & \multirow{3}{*}{$\begin{array}{c}\text { Swell } \\
\\
(\%)\end{array}$} & \multirow{3}{*}{ LL } & \multirow{3}{*}{ PI } & \multirow{3}{*}{ LAA $(\%)$} & \multirow{3}{*}{ Soundness (\%) } \\
\hline & & & & & & & & & & \\
\hline & & $\mathrm{OMC}(\%)$ & $\gamma_{\mathrm{d}, \max }\left(\mathrm{t} / \mathrm{m}^{3}\right)$ & & & & & & & \\
\hline SB01 & Nalao & 10.50 & 2.12 & - & - & - & 29.00 & 16.40 & - & - \\
\hline SB02 & Kittiwadee & 16.10 & 2.02 & - & - & - & 37.50 & 12.37 & - & - \\
\hline SB03 & Highway 1013 Sanpathong - Bankard & 14.22 & 1.89 & - & - & - & 37.00 & 18.55 & - & - \\
\hline SB04 & Phathai & 15.20 & 1.93 & - & - & - & 35.00 & 13.49 & - & - \\
\hline SB05 & Phonepheng & 14.00 & 2.01 & - & - & - & 34.10 & 14.94 & - & - \\
\hline SB06 & Highway 1280 & 12.80 & 1.91 & - & - & - & 39.00 & 18.62 & - & - \\
\hline SB07 & Banguay & 14.80 & 1.95 & - & - & - & 34.00 & 16.54 & - & - \\
\hline SB08 & Ban Charng Tang Kajard & 7.70 & 2.12 & - & - & - & NP & NP & - & - \\
\hline SB09 & Sattaheeb & 8.50 & 2.05 & - & - & - & NP & NP & - & - \\
\hline SB10 & Na Ngua & 9.79 & 2.08 & - & - & - & NP & NP & - & - \\
\hline B01 & Dontue & 9.17 & 2.17 & - & - & - & 27.00 & 13.00 & 43.13 & - \\
\hline B02 & Highway 11 Lumpang - Denchai & 7.00 & 2.16 & - & - & - & 28.30 & 13.50 & 35.55 & - \\
\hline B03 & Bansaew & 10.00 & 1.99 & - & - & - & NP & NP & 59.69 & - \\
\hline B04 & Pha Singh & 8.85 & 2.08 & - & - & - & 30.00 & 11.92 & 34.82 & - \\
\hline B05 & Nongmeg & 9.50 & 2.19 & - & - & - & 24.50 & 13.23 & 41.63 & - \\
\hline B06 & Klongsai & 9.80 & 2.07 & - & - & - & NP & $\mathrm{NP}$ & 40.74 & - \\
\hline B07 & Highway 4 Krabi - Klongthom & 7.00 & 2.22 & - & - & - & 29.00 & 8.08 & 33.32 & - \\
\hline B08 & Kraburi & 7.00 & 2.21 & - & - & - & 21.00 & 12.08 & 45.36 & - \\
\hline B09 & Bansamut & 10.80 & 2.18 & - & - & - & 31.00 & 12.17 & 48.69 & - \\
\hline B10 & Bohphuphan & 8.00 & 2.16 & - & - & - & NP & NP & 53.83 & - \\
\hline $\mathrm{C} 01$ & Silaphran & 6.60 & 2.36 & 149.5 & 130.7 & 0.010 & $\mathrm{NP}$ & NP & 30.82 & 3.40 \\
\hline $\mathrm{C} 02$ & Highway 1280 & 7.58 & 2.12 & 100 & 89.3 & 0.170 & NP & $\mathrm{NP}$ & 29.30 & 4.97 \\
\hline $\mathrm{C} 03$ & Burirum Ratchada & 10.80 & 2.14 & 98.7 & 84 & 0.260 & NP & $\mathrm{NP}$ & 18.61 & 4.80 \\
\hline $\mathrm{C} 04$ & Kittiwadee & 10.00 & 2.20 & 124 & 90 & 0.108 & $\mathrm{NP}$ & $\mathrm{NP}$ & 19.69 & 7.36 \\
\hline $\mathrm{C} 05$ & Sahasilaloei & 5.50 & 2.28 & 105.3 & 81.3 & 0.108 & NP & $\mathrm{NP}$ & 34.74 & 8.89 \\
\hline $\mathrm{C} 06$ & Asian & 5.80 & 2.28 & 118.7 & 100 & 0.195 & NP & $\mathrm{NP}$ & 34.23 & 3.94 \\
\hline $\mathrm{C} 07$ & Banmueng Wangphai & 7.80 & 2.11 & 158.7 & 120 & 0.043 & NP & NP & 33.61 & 2.53 \\
\hline $\mathrm{C} 08$ & Silathong & 6.90 & 2.26 & 99.3 & 80.7 & 0.010 & NP & NP & 31.78 & 2.83 \\
\hline $\mathrm{C} 09$ & Ananta Sila & 7.30 & 2.27 & 140 & 94.7 & 0.032 & NP & $\mathrm{NP}$ & 38.21 & 2.52 \\
\hline $\mathrm{C} 10$ & Amornphan & 8.30 & 2.23 & 84 & 80 & 0.130 & NP & $\mathrm{NP}$ & 31.78 & 4.82 \\
\hline R01 & Higway 41 Sta. $183+700$ & 5.80 & 2.21 & - & - & - & NP & NP & - & - \\
\hline R02 & Highway 112 Khamphangphet Bypass Route & 6.90 & 2.15 & - & - & - & NP & NP & - & - \\
\hline $\mathrm{R} 03$ & Highway 1109 Wangjao - Lokoh & 7.90 & 2.14 & - & - & - & $\mathrm{NP}$ & $\mathrm{NP}$ & - & - \\
\hline R04 & Highway 43 Janan - Padae & 11.00 & 1.92 & - & - & - & NP & $\mathrm{NP}$ & - & - \\
\hline R05 & Highway 43 Padae - Porkoh & 9.30 & 2.04 & - & - & - & $\mathrm{NP}$ & $\mathrm{NP}$ & - & - \\
\hline R06 & Highway 323 & 7.42 & 2.20 & - & - & - & NP & NP & - & - \\
\hline R07 & Recycling Sahakhonsong Authai & 10.00 & 2.06 & - & - & - & $\mathrm{NP}$ & $\mathrm{NP}$ & - & - \\
\hline R08 & Highway 12 Sta 168 & 8.60 & 2.11 & - & - & - & $\mathrm{NP}$ & $\mathrm{NP}$ & - & - \\
\hline R09 & Highway 12 Sta 619 & 14.25 & 1.91 & - & - & - & NP & $\mathrm{NP}$ & - & - \\
\hline $\mathrm{R} 10$ & Highway 12 Sta $211+500$ & 8.70 & 2.11 & - & - & - & $\mathrm{NP}$ & $\mathrm{NP}$ & - & - \\
\hline
\end{tabular}

\subsection{Free-Free Resonance (FFR) Test}

FFR tests were performed in this study to assess low-strain resonant frequency and hence shear wave velocity of the samples using Equation 1 where vs = shear wave velocity, $\mathrm{f}=$ resonant frequency, $\lambda=$ wavelength, and $\mathrm{L}=$ sample length .The low-strain shear waves were generated by tapping perpendicularly at the end of the hanged sample using a developed small hammer, as shown in Figure 5 .The hammer was built from a wooden stick with a weight attached at one end to minimize loss of seismic energy due to resonance in the hammer itself .The waves were recorded in time domain by an accelerometer which was attached horizontally at the other end of the sample. The response was subsequently Fourier transformed into frequency domain using a spectrum analyzer to locate the resonant frequency )the frequency of the maximum peak amplitude in Fourier spectra (of the sample. An example of a resonant frequency obtained from this study is demonstrated in Figure 6.

$$
v_{s}=f \lambda=2 f L
$$




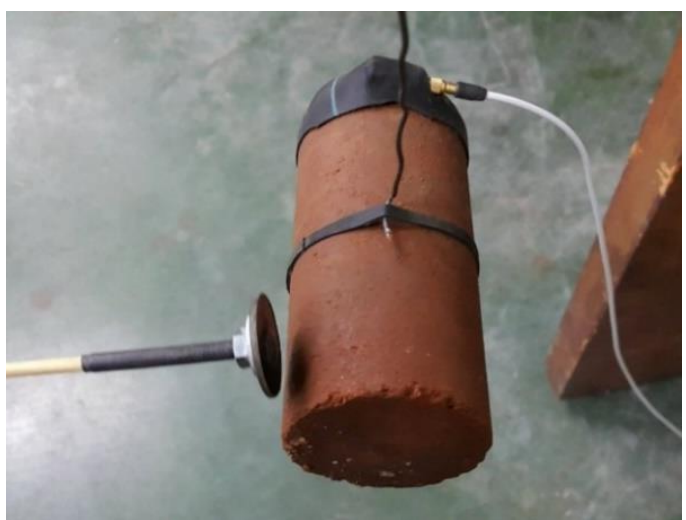

Fig. 5: Generating of Shear Waves in FFR Test.

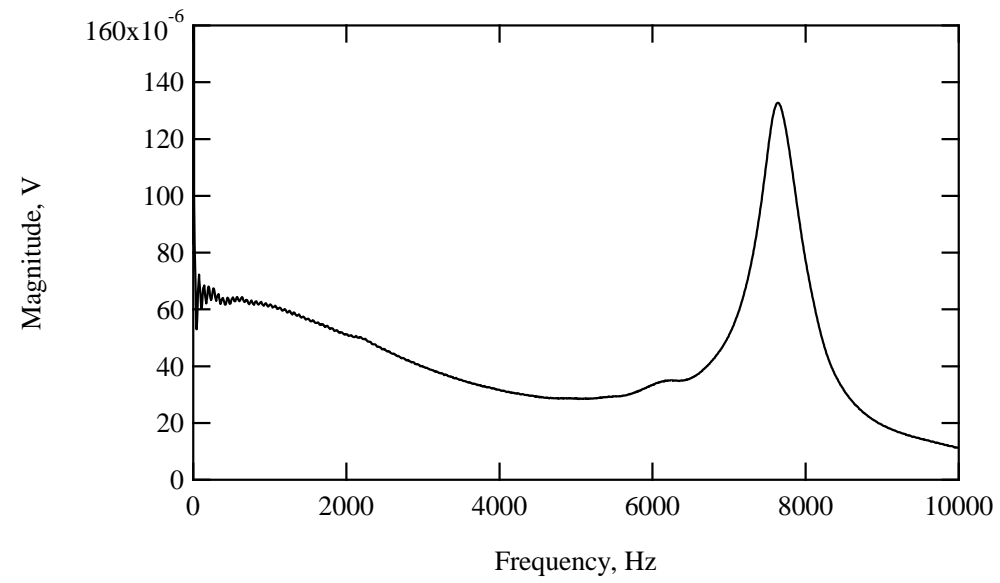

Fig. 6: An Example of Resonant Frequency of a Pavement Recycling Material with 3\% Cement Ratio.

\subsection{Unconfined Compressive Strength (UCS) Test}

UCS tests were performed right after completion of the FFR tests. The test was conducted accordingly to [4] which is equivalent to the AASHTO T208 standard. A photograph and an example of the result of UCS test are shown in Figure 7 and Figure 8, respectively.

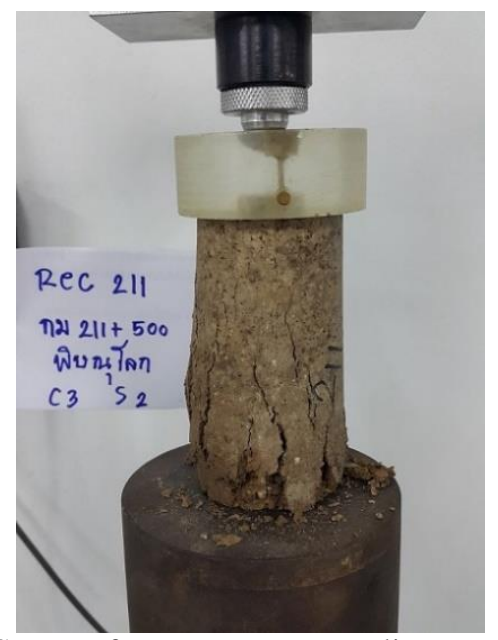

Fig. 7: A Photograph of UCS Test of a Pavement Recycling Material with 3\% Cement Ratio. 


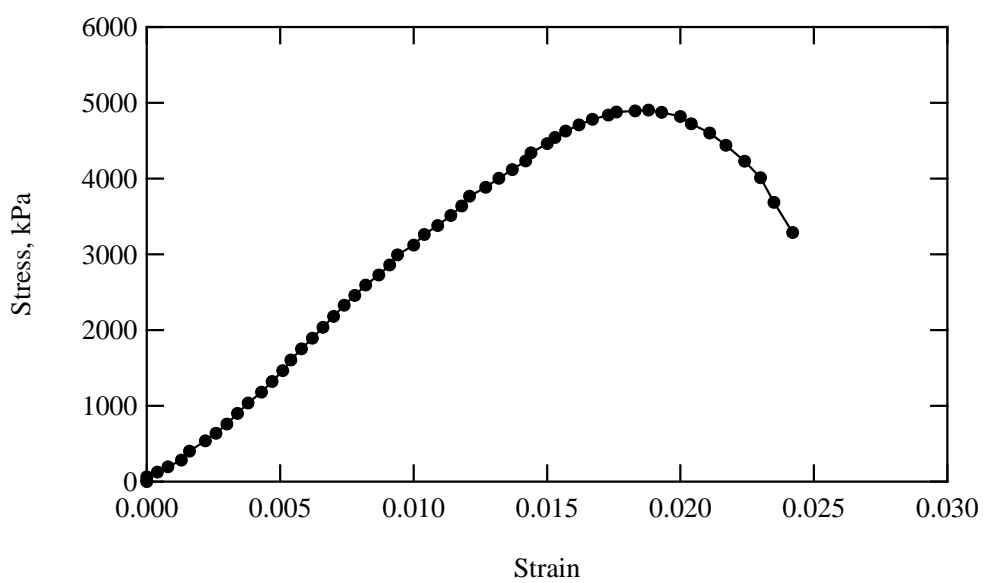

Fig. 8: An Example of UCS of a Pavement Recycling Material with 3\% Cement Ratio.

\section{Data Analysis}

\subsection{Effect of Cement Ratio and Fine Particle Content to Shear Wave Velocity and Unconfined Compressive Strength}

The effect of cement ratio to shear wave velocity and unconfined compressive strength )UCS( of the 4 mentioned materials was studied .The results indicated that shear wave velocity increased nonlinearly with increasing cement ratio as shown in Figure 9 while UCS increased more linearly with increasing cement ratio as shown in Figure 10 for all materials . The results also showed that at the same cement ratio, soil cement subbase and soil cement base )both were originally lateritic soils (provided the lowest and second lowest shear wave velocity, respectively .On the other hand, cement modified crushed rock base and pavement recycling provided much higher shear wave velocity than those soil cement materials. These results certainly suggest that the higher the fine particle content in the sample, the lower the shear wave velocity and thus the lower the stiffness of the sample. Similar trends were also noticed for UCS of the same materials which coincided with [9].

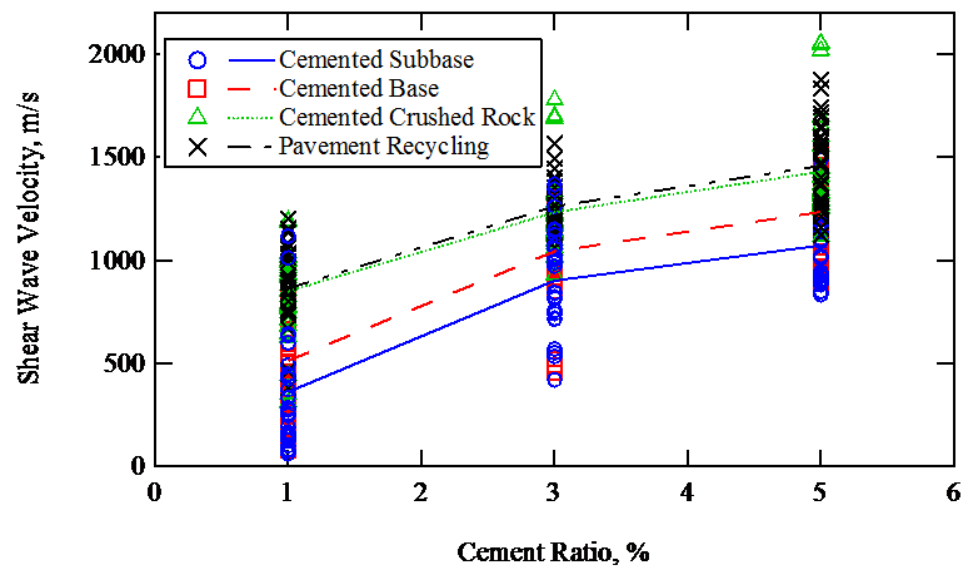

Fig. 9: Comparison of Effect of Cement Ratio to Shear Wave Velocity of Different Cement Stabilized Materials. 


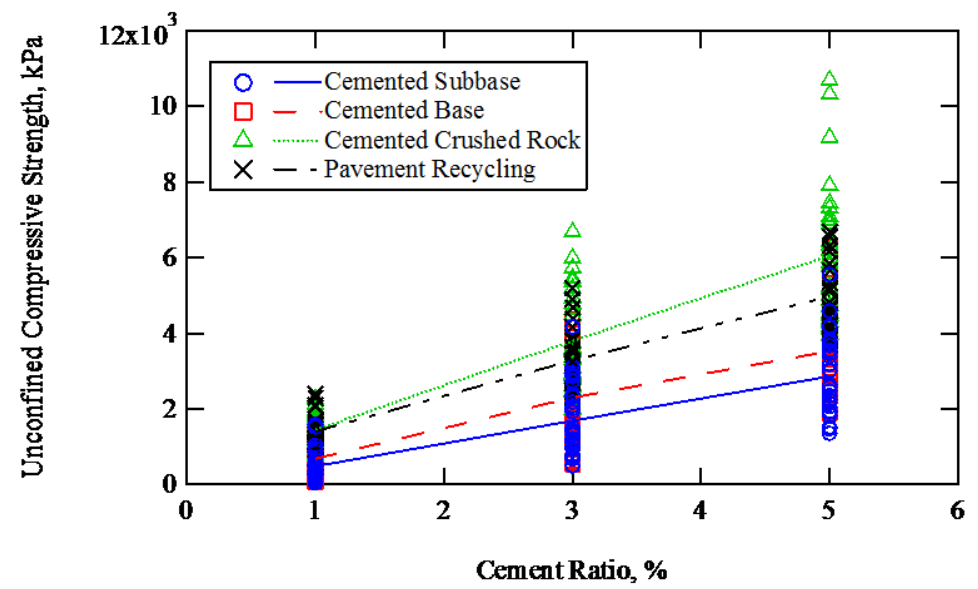

Fig. 10: Comparison of Effect of Cement Ratio to UCS of Different Cement Stabilized Materials.

\subsection{Relationship between Shear wave velocity and Unconfined Compressive Strength}

Empirical relationships between shear wave velocity and UCS were created to develop quality control index of the materials. The results showed that shear wave velocity increased nonlinearly with UCS, with percent errors ranged in between $20-30 \%$, as shown in Figure 11, Figure 12, Figure 13, and Figure 14 for soil cement subbase, soil cement base, cement modified crushed rock base, and pavement recycling, respectively .Comparing to other studies, the results demonstrated good agreement, at the same range of UCS, with deep mixing soil cement [2] and cement stabilized Kaolin and PALF )PALF -Pineapple Leaf Fibers( [3] as presented in Figure 15.

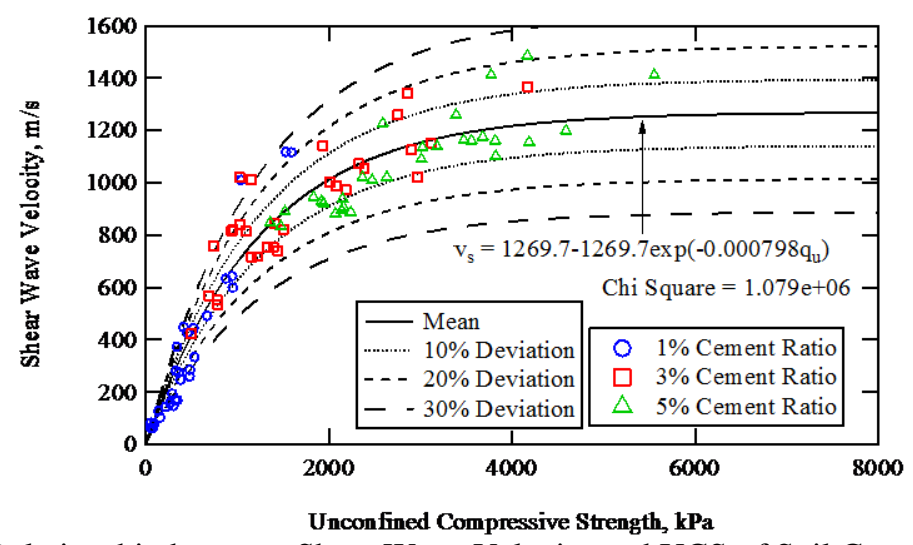

Fig. 11: Relationship between Shear Wave Velocity and UCS of Soil Cement Subbase.

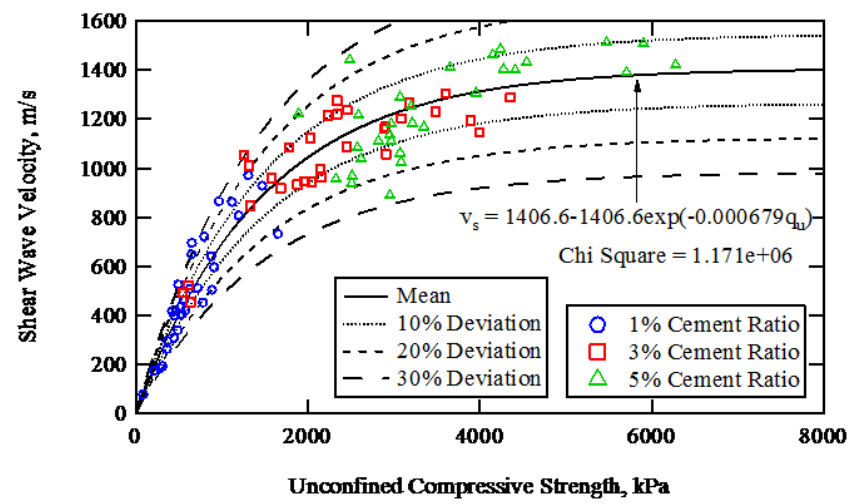

Fig. 12: Relationship between Shear Wave Velocity and UCS of Soil Cement Base. 


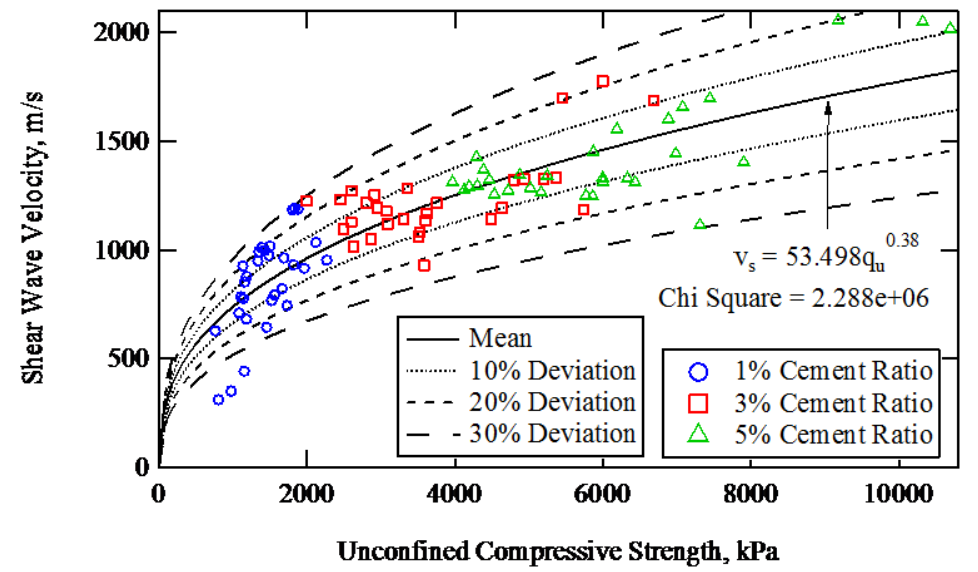

Fig. 13: Relationship between Shear Wave Velocity and UCS of Cement Modified Crushed Rock Base.

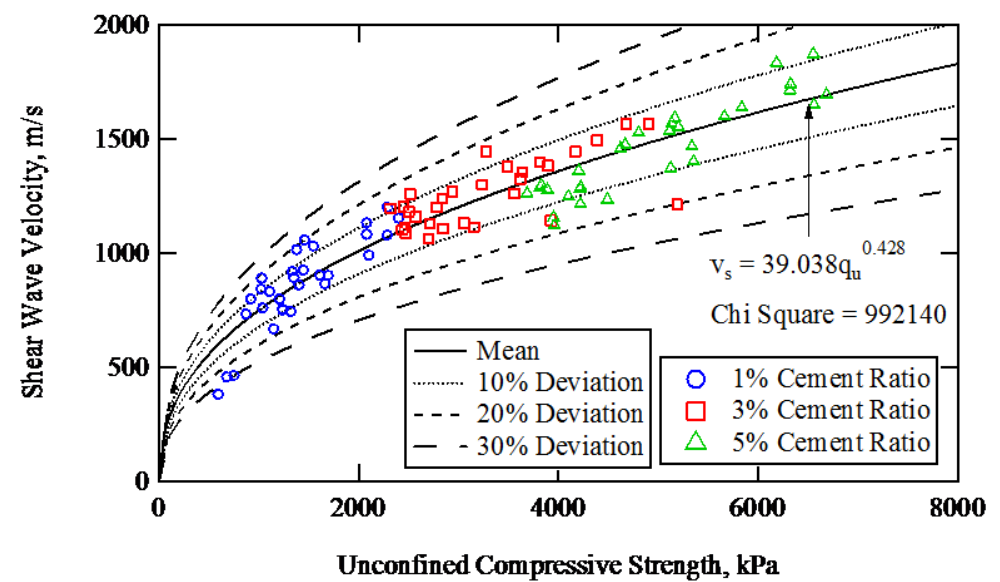

Fig. 14: Relationship between Shear Wave Velocity and UCS of Pavement Recycling.

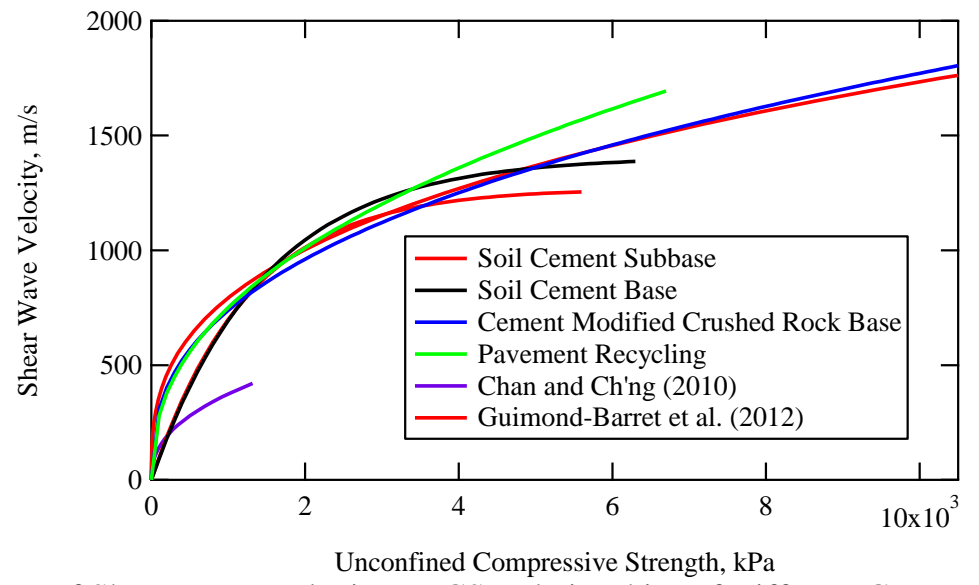

Fig. 15: Comparison of Shear Wave Velocity - UCS Relationships of Different Cement Stabilized Materials.

\subsection{Using Shear Wave Velocity as Quality Control Index for Cement Stabilized Road Structures}

In previous studies, shear wave velocity was used to investigate stiffness of subbase and subgrade materials, and was correlated with California Bearing Ratio or Dynamic Cone Penetration [11] - [12]. However, according to DOH standards, to ensure that cement stabilized materials have good construction quality their UCS have to be higher than the minimum 
requirement, $689 \mathrm{kPa}$ (100 psi) for soil cement subbase, $1724 \mathrm{kPa}$ (200 psi) for soil cement base, and $2413 \mathrm{kPa}$ (350 psi) for both cement modified crushed rock base and pavement recycling. However, as doing UCS test at construction sites requires coring and borehole repairing, it is considered as a destructive, inconvenient and time-consuming method. To facilitate nondestructive, more convenient, and less time-consuming quality control methods, shear wave velocity, which can be measured using many low-strain seismic tests, is introduced as a quality control index. According to the results of this study, to ensure that cement stabilized materials have good construction quality their shear wave velocities, back calculated using empirical equations of previous section, have to be higher than the numbers presented in Table 2.

Table 2: Quality Control Index of Cement Stabilized Materials.

\begin{tabular}{|l|c|c|c|}
\hline \multirow{2}{*}{ Material } & \multicolumn{2}{|c|}{ Unconfined Compressive Strength } & Shear Wave Velocity (m/sec) \\
\cline { 2 - 3 } & $\mathrm{kPa}$ & Psi & \\
\hline Soil Cement Subbase & 689 & 100 & 536 \\
\hline Soil Cement Base & 1724 & 200 & 971 \\
\hline Cement Modified Crushed Rock Base & 2413 & 350 & 1033 \\
\hline Pavement Recycling & 2413 & 350 & 1095 \\
\hline
\end{tabular}

\section{Conclusions and Recommendations}

This study presented the effect of the amount of cement and amount of fine content on shear wave velocity and UCS of 4 types of cement stabilized materials including soil cement subbase, soil cement base, cement modified crushed rock base, and pavement recycling. The results showed that the increase of cement ratio increased both shear wave velocity and UCS while the increase of fine particles in the material decreased both shear wave velocity and UCS of all materials. The study also introduced the possibility of using shear wave velocity, as an alternative to conventional, unconfined compressive strength, as a quality control index. The minimum required shear wave velocity of constructions of soil cement subbase, soil cement base, cement modified crushed rock base, and pavement recycling should be 536, 970,1033 and $1095 \mathrm{~m} / \mathrm{sec}$, respectively. These numbers are very useful for the quality control of any site constructions using cement stabilized materials because shear wave velocity can be measured quicker and more conveniently than the UCS test.

Nonetheless, this study was only performed under laboratory conditions so many factors in the field such as overburden pressure, changing moisture content and temperature, or even the curing method used during construction were not included. These factors could also affect shear wave velocity and the strength of cement stabilized materials. Therefore, further in-situ tests are required to be conducted to obtain detailed information of possible modifying factors.

\section{Acknowledgements}

The authors would like to thank Department of Highway of Thailand (DOH) for the supporting fund and the supports from their staff throughout the research project. We are very thankful to Prof. Duncan R. Smith, Ms. Auncharee Nirachanon, and Ms. Klairung Srikokcharoen for their kindly help editing this manuscript.

\section{References}

[1] Standard Test Method for Fundamental Transverse, Longitudinal and Torsional Resonant Frequencies of Concrete Specimens, ASTM C 215, 1999.

[2] A. Guimond-Barrett, E. Nauleau, A. Le Kouby, A. Pantet, P. Reiffsteck and F. Martineau, "Free-free resonance testing of in situ deep mixed soils," Geotechnical Testing Journal, vol. 36, no. 2, 2012.

[3] C. M. Chan and S. S. Ch'ng, "Preliminary study of s-wave velocity and unconfined compressive strength of cement - palf stabilised kaolin", International Journal of Integrated Engineering, vol. 2, no. 2, 2010.

[4] Standard Test Method for Unconfined Compressive Strength of Soil, DH-T 105/1972.

[5] Standard of Soil Cement Subbase, DH-S 206/2532, 1989.

[6] Standard of Pavement Recycling, DH-S 213/2543, 2000.

[7] Standard of Cement Modified Crushed Rock Base, DH-S 203/2556, 2013a.

[8] Standard of Soil Cement Base, DH-S 204/2556, $2013 \mathrm{~b}$.

[9] R. Saadeldin and S. Siddiqua, "Geotechnical characterization of a clay-cement mix," Bulletin of Engineering Geology and the Environment, vol. 72, no. 3, pp. 601-608, 2013. 
[10] R. D. Verastegui-Flores, G. Di Emidio, A. Bezuijen, J. Vanwalleghem and M. Kersemans, "Evaluation of the freefree resonant frequency method to determine stiffness moduli of cement-treated soil," Soils and Foundations, vol. 55, no. 5, pp. 943-950, 2015.

[11] S. A. Rosyidi, K. A. M. Nayan, M. R. Taha and A. Ismail, "Estimating G-max of soil subgrade using a seismic method," The-e Journal of Non Destructive Testing, vol. 11, no. 6, 2006.

[12] S. A. Rosyidi, M. R. Taha, K. A. M. Nayan, Z. Chik and M. Siegfried, "Development of Vs-CBR-DCP empirical model for determining dynamic stiffness of pavement base layer using SASW," in Proceedings of the International Conference on Advanced Characterization of Pavement and Soil Engineering Materials, vol. 1, pp. 895-902, 2007. 